\title{
Optimal management of severe nausea and vomiting in migraine: improving patient outcomes
}

This article was published in the following Dove Press journal:

Patient Related Outcome Measures

10 October 2013

Number of times this article has been viewed

Miguel JA Láinez ${ }^{1,2}$

Ana García-Casado'

Francisco Gascón'

'Servicio de Neurología, Hospital Clínico Universitario, Valencia, Spain;

${ }^{2}$ Departamento de Neurología, Universidad Católica de Valencia, Valencia, Spain
Correspondence: Miguel JA Láinez Servicio de Neurología, Hospital Clínico Universitario, 17 Avinguda Blasco Ibáñez, Valencia 460I0, Spain Tel +34963868 863

Fax +34963987812

Email jlaineza@meditex.es
Abstract: Migraine is a common and potentially disabling disorder for patients, with wide-reaching implications for health care services, society, and the economy. Nausea and vomiting during migraine attacks are common symptoms that affect at least $60 \%$ of patients suffering from migraines. These symptoms are often more disabling than the headache itself, causing a great burden on the patient's life. Nausea and vomiting may delay the use of oral abortive medication or interfere with oral drug absorption. Therefore, they can hinder significantly the management and treatment of migraine (which is usually given orally). The main treatment of pain-associated symptoms of migraine (such as nausea and vomiting) is to stop the migraine attack itself as soon as possible, with the effective drugs at the effective doses, seeking if necessary alternative routes of administration. In some cases, intravenous antiemetic drugs are able to relieve a migraine attack and associated symptoms like nausea and vomiting. We performed an exhaustive PubMed search of the English literature to find studies about management of migraine and its associated symptoms. Search terms were migraine, nausea, and vomiting. We did not limit our search to a specific time period. We focused on clinical efficacy and tolerance of the various drugs and procedures based on data from human studies. We included the best available studies for each discussed drug or procedure. These ranged from randomized controlled trials for some treatments to small case series for others. Recently updated books and manuals on neurology and headache were also consulted. We herein review the efficacy of the different approaches in order to manage nausea and vomiting for migraine patents.

Keywords: migraine, nausea, vomiting, management, treatment

\section{Introduction}

Migraine is a common disorder that affects approximately $10 \%-12 \%$ of the population of developed countries (18\% of women and $6 \%$ of men), with similar prevalence rates in North America and Europe. It has peak prevalence between the fourth and fifth decades of life. ${ }^{1}$

During a migraine attack, the primary symptom is typically headache. Migraine attacks are associated with other accompanying and varied symptoms. Photophobia and phonophobia are the most frequent symptoms, followed by nausea and vomiting, and less frequently osmophobia and kinetophobia (worsening of pain with head movements). Nausea and vomiting may appear at the same time as pain. Nevertheless, they usually start 1 hour after the beginning of the headache. ${ }^{2}$

Often, the accompanying symptoms of migraine can be as annoying and disturbing, or even more so, than the headache itself. Moreover, the most bothersome symptoms belong to the gastrointestinal area, and impede many patients from eating 
during the episodes (because of nausea and fear of vomiting). This is why it is important to inquire about symptoms in great detail. ${ }^{3-7}$

Approximately, 60\%-95\% and 50\%-62\% of patients with migraines develop nausea and vomiting, respectively, during migraine attacks. ${ }^{1,2}$ The American Migraine Study II stated that $73 \%$ of study patients with migraines had suffered from nausea during attacks, and that $29 \%$ had vomited. ${ }^{8}$ In other studies, nausea occurred in more than $90 \%$ of all patients with migraines (nearly one-third of them had nausea during every attack), and vomiting occurred in almost $70 \%$ of all patients with migraines (nearly one-third of them vomited in the majority of attacks). Indeed, $30.5 \%$ of those who had nausea reported that it interfered with their ability to take their oral migraine medication. ${ }^{9}$

Nausea and vomiting significantly hinder migraine management by limiting oral absorption of treatments in some cases, causing more burden on the patient's quality of life. There is a correlation between the presence of these symptoms and the severity of migraine pain.

Severe migraine episodes that last more than 72 hours with not more than 4 hours of pain relief during that period are defined as status migrainosus. They are usually accompanied by severe nausea and vomiting that can be profuse and overflowing, causing dehydration and precluding oral administration of drugs. In these cases, fluid and electrolyte replacement and parenteral treatment are required to enable absorption of drugs.

\section{Pathophysiology}

The pathophysiology of migraine has long been debated and remains incompletely understood. A complex network of nuclei with different functions forms the pain system. In a simplified way, the pain matrix may be divided in two: the peripheral and the central systems. The peripheral system, whose main role is pain location, is composed of the trigeminal system and the trigeminal lemniscus. The central system, whose main function is to process the pain signals, is formed by the periaqueductal gray matter, the locus coeruleus, and the reticular formation, among others. ${ }^{1}$

Headache is caused by the activation of intracranial pain-sensitive structures (arteries of the circle of Willis and the first few centimeters of their medium-sized branches, meningeal-dural arteries, large veins and dural venous sinuses, and portions of the dura near blood vessels). The painful impulses originating in extracranial structures are conducted mainly through cranial nerves V, VII, IX, and X. ${ }^{2}$ These painful inputs arrive to the spinal trigeminal nucleus, where they are modified and modulated by excitatory and inhibitory brain-stem pathways that connect with the periaqueductal gray matter, the rostral ventromedial medulla, the locus coeruleus, and the dorsal raphe nucleus. ${ }^{2}$

The nociceptive and thermal-sensitive neurons originating at the trigeminal caudal nucleus cross the midline and join the contralateral spinothalamic tract, directing their projections to the thalamus through the trigeminal lemniscus. ${ }^{10}$ These neurons originating at the trigeminal caudal nucleus also connect with structures involved in visceral and somatic unconscious reflexes, such as the solitary tract nucleus, the superior colliculus, the cerebellum, and the inferior olive. ${ }^{1}$

Serotonergic neurons are located mainly in the raphe nuclei in the brain stem. The importance of the role of the brain stem in migraine is not yet clarified. Nevertheless, it is known that it contains many binding sites of effective drugs used for the treatment of migraine, and there are positron emission tomography studies that show continuous activation of brain-stem cells in patients with migraines. Therefore, the brain stem's role in migraine must be important. ${ }^{11}$ At the same time, it has been suggested that the cortical spreading depression wave generated in migraine's aura activates the afferent pathways of the trigeminovascular system, triggering a set of responses at the cortical meninges and the brain stem that are responsible for the headache. ${ }^{12}$

Migraine triggers activate multiple hypothalamic, limbic, and cortical areas, all of which contain neurons that project to the preganglionic parasympathetic neurons in the superior salivatory nucleus. This nucleus, in turn, activates postganglionic parasympathetic neurons in the sphenopalatine ganglion, resulting in vasodilation and local release of inflammatory molecules that activate meningeal nociceptors. ${ }^{13}$ There is a reflex connection between neurons in the pons in the superior salivatory nucleus, which results in a cranial parasympathetic outflow that is mediated through the pterygopalatine, otic, and carotid ganglia. ${ }^{14}$ Activation of the superior salivatory nucleus has been frequently described in migraine, suggesting nausea and vomiting is of central origin.

\section{Gastrointestinal symptoms in migraine}

Gastrointestinal symptoms in migraine are very frequent. More than two-thirds of patients with migraine experience vomiting during their migraine attacks. ${ }^{15,16}$ Both nausea and vomiting are usually related to the intensity of pain, ${ }^{17,18}$ although the exact link between pain and gastrointestinal symptoms in patients with migraines is not completely understood.

There is evidence that migraine patients have an increased tendency for nausea and vomiting after surgery compared to 
nonmigraine patients. ${ }^{18,19}$ Nausea is a predominant symptom of migraine, and the basis of it was thought to be gastric stasis. ${ }^{19,20}$ Several studies on gastric stasis based on indirect evidence of gastric emptying have assumed that gastric stasis is the underlying mechanism of nausea, which is a predominant symptom of migraine, and the studies were based on that theory. However, today we know that when improving gastric stasis in migraineurs with a migraine attack, nausea still remains until we successfully treat the migraine attack. So we must assume that gastric stasis is an epiphenomenon but not the cause of nausea and vomiting, which is a central process.

Drug absorption studies provided in the 1970s and 1980s using aspirin, aspirin in combination with metoclopramide, and paracetamol in combination with tolfenamic acid concluded that there is a gastric stasis or some form of delayed emptying of the stomach during acute migraine attacks. ${ }^{21}$ These studies assumed that the rate-limiting step in the absorption of these drugs was the rate of emptying the drug from the stomach, and the delay in absorption, as measured by time to peak concentration and area under the curve at $0-2$ hours. As this was observed only during the acute attack, it was concluded erroneously that gastric stasis is present only during an acute migraine attack.

In a study with effervescent aspirin tablets in migraine patients and healthy controls, the rate of absorption was found to be reduced relative to that found in nonmigraine patients and in migraine patients outside of a migraine attack. ${ }^{22}$ Those subjects with delayed absorption were more likely to have delayed responses and require additional treatment. The bioavailability of aspirin was improved when combined with metoclopramide compared with aspirin alone. ${ }^{23}$ Similar results have been demonstrated with paracetamol and coadministration of metoclopramide. ${ }^{24}$

Nevertheless, there are many methodological problems with all these studies on gastroparesis as the cause of nausea, and further studies are required. Even more, some works on gastroparesis as the reason for nausea in migraine show contrary results. Tokola et al used gastric scintigraphy to study gastric stasis in migraine patients (both ictally and interictally) compared with nonmigrainous controls. Most of the migraine patients met or nearly met the clinical diagnostic criteria for gastroparesis ictally (78\%) and interictally (80\%). ${ }^{25-27}$ Aurora et al concluded, contrary to previous belief, that migraine patients suffer from gastric stasis both during and outside an acute migraine attack. Therefore, they suggest that migraine patients may have an abnormal autonomic function compared to nonmigrainous controls. Another interesting observation from their study is the absence of correlation between clinical symptoms of nausea and gastric stasis.
Aurora et al suggest that a central process, due to changes occurring in the brain stem as a part of the acute migraine, rather than due to gastric stasis, causes nausea, as the stasis is present even outside an attack, and none of their patients was nauseous outside an attack. ${ }^{21}$

Triptans increase gastric stasis; however, they also improve all migraine symptoms, including nausea. Therefore, it can be assumed that if triptans relieve nausea, the nausea must be a central phenomenon that forms part of the acute-migraine central process, which ends with triptan administration.

It has been suggested that nausea in migraine is probably a result of parasympathetic activation. The central effect on $\mathrm{D}_{2}$ receptors in dopaminergic antagonists shows that they act in the central nervous system instead of having a direct gastric effect. More studies are needed to clarify what causes gastric stasis in migraine patients. One main target to be studied is the autonomic nervous system. Several clinical observations have found autonomic abnormalities in patients with migraine compared to normal controls. ${ }^{28-31}$

The periaqueductal gray matter in the brain stem is the center of a powerful descending sympathetic network. Dysfunctional periaqueductal gray matter with iron accumulation not related with patients' age, has been observed in migraineurs. These findings may be due to iron-catalyzed, free radical cell damage. ${ }^{32}$ The hypothalamus, which is the main area of the brain that controls the autonomic system, has been suggested as an area that triggers migraine. Therefore, the autonomic nervous system must play an important role in migraine patients, although further studies are needed.

Cyclic vomiting syndrome (CVS) in children is considered a migraine equivalent. CVS is an episodic nausea and nonbilious vomiting disorder characterized by recurrent stereotypic symptoms with disease-free intervals. CVS typically develops during childhood, usually between the ages of 3 and 7 years; although it often remits during adolescence, it can persist into adult life. CVS is associated with a high prevalence of migraine, and is commonly considered a precursor to migraine. ${ }^{1,2}$ It often responds to migraine treatment, like amitriptyline in preventive treatment and nonoral sumatriptan as abortive treatment. ${ }^{33,34}$

\section{Management of nausea and vomiting in migraine}

Migraine is a very common disorder. Nevertheless, only about $50 \%$ of patients who have migraine headaches know this is their diagnosis, and among that group of patients, optimum therapy is being given to only about half of them. ${ }^{35}$

Acute treatment attempts to stop the progression of an attack and relieve pain and functional impairment 
once an attack has begun, whereas preventive therapy is given to reduce attack frequency and severity. Additional benefits of preventive therapy include improvement of responsiveness to acute abortive treatment and reduction of disability. The treatment plan should be reassessed at regular intervals.

The main goal of migraine management, in the majority of patients, is to initiate the abortive treatment as soon as possible once the migraine attack has started. The efficacy of acute-migraine treatment is much improved if medication is used early during an attack before central sensitization begins. ${ }^{36,37}$

The development of throbbing in the initial phase of migraine is mediated by sensitization of peripheral trigeminovascular neurons that innervate the meninges, and the development and maintenance of cutaneous allodynia later in the attack is propelled by sensitization of central trigeminovascular neurons that receive converging sensory input from the meninges as well as from the scalp and facial skin. ${ }^{1,2}$

Self-treatment of migraine can relieve nausea and vomiting in many cases too. Trying to avoid individual stimuli that trigger nausea and vomiting in some patients (such as particular meals or odors) may also be recommended.

Oral medications are usually less effective once the event has begun, due to gastrointestinal motility and bioavailability decrease. In patients with nausea, oral drugs may be effective. Nevertheless, if the patients are vomiting, the route of administration of drugs should not be oral. In these cases, the treatment should be administered parenterally, intranasally, or rectally to guarantee their absorption.

The oral bioavailability of many drugs, including triptans, is lower when they are administered during the migraine attack. ${ }^{2,8}$ Prokinetic and antiemetic drugs, such as metoclopramide, improve intestinal motility even when vomiting is not present. Therefore, treatment with analgesics and/or triptans may be combined with metoclopramide or other antiemetics, such as domperidone, to improve the response to oral medications, especially in patients with partial responses to acute treatment or with high recurrence rates. ${ }^{6}$

In Table 1, there is a summary of the most common abortive drugs used in migraine, doses, and characteristics. In Table 2, there is a summary of the specific management of nausea and vomiting in migraine.

\section{NSAIDs}

A number of trials have shown that nonsteroidal antiinflammatory drugs (NSAIDs) are effective in treating migraine episodes. It is well known that NSAIDs, such as aspirin, ibuprofen, naproxen, ketorolac, and diclofenac, are effective in migraine attacks, relieving both pain and the accompanying symptoms. ${ }^{37-42}$

The expert recommendations on NSAID use in migraine are to give, at the onset of pain, doses higher than the usual ones (most commonly a double dose), and to administer them as soon as possible. ${ }^{43}$ On the other hand, NSAIDs have the advantage that they can be combined with triptans with an excellent synergistic effect.

Several studies have proved the efficacy of ibuprofen in acute treatment of migraine. There is evidence that higher doses correlate with a better response to treatment and that soluble formulations are better. In some studies, associated symptoms, such as nausea and vomiting, were also reduced. Nevertheless, complete relief of pain and associated symptoms occurs only in a minority of patients. ${ }^{44}$

Some studies have demonstrated that the efficacy of $1,000 \mathrm{mg}$ of aspirin as acute abortive treatment of migraine attacks is similar to sumatriptan $50 \mathrm{mg} .^{45}$ The remission of accompanying symptoms revealed no significant differences between aspirin and sumatriptan. Aspirin has a better sideeffect profile than sumatriptan. ${ }^{46}$

Patients who have a high frequency of nausea and vomiting during their migraines should combine an oral antiemetic (such as $10 \mathrm{mg}$ of metoclopramide or domperidone) with NSAIDs before the onset of nausea and vomiting. ${ }^{47}$ Metoclopramide decreases and counteracts the gastric stasis associated with migraine, enhancing the rate of bioavailability of NSAIDs. Recently, a bilayer tablet of metoclopramide and diclofenac in separated layers has been developed to avoid drug incompatibility, increasing the efficacy of both in combination. ${ }^{48}$

When the oral route is ineffective or is not possible due to intense nausea and vomiting, parenteral NSAIDs are very useful. Ketorolac doses of 30-60 mg and dexketoprofen doses of $50 \mathrm{mg}$ (unavailable in the US but frequently used in Europe) are a good option in these cases. ${ }^{49}$ A clinical trial evaluated the efficacy and safety of an intranasal formulation of ketorolac tromethamine containing $6 \%$ lidocaine versus placebo. Patients receiving ketorolac showed a significant improvement in pain relief compared with those who received placebo, and it was well tolerated. Associated migraine symptoms were significantly improved with ketorolac relative to placebo at several time points. ${ }^{50}$

Intravenous lysine-acetylsalicylic acid is also an effective and safe drug for the parenteral treatment of acute migraine 
Table I Common drugs used as abortive treatment in migraine attacks

\begin{tabular}{|c|c|c|c|c|}
\hline & Dose & $\begin{array}{l}\text { Route of } \\
\text { administration }\end{array}$ & Advantages & Disadvantages \\
\hline NSAIDs & $\begin{array}{l}\text { Higher than usually used for } \\
\text { other types of pain } \\
\text { - ASA: I g } \\
\text { - Ibuprofen: } 800-1,200 \mathrm{mg} \\
\text { - Dexketoprofen: } 50 \mathrm{mg} \\
\text { - Naproxen } 1,000 \mathrm{mg} \\
\text { - Ketoprofen } 75 \mathrm{mg} \\
\text { - Ketorolac oral } 20 \mathrm{mg} \text { or } \\
\text { intramuscular } 60 \mathrm{mg} \\
\text { - Indomethacin } 50 \mathrm{mg}\end{array}$ & $\begin{array}{l}\text { Oral, rectal, } \\
\text { intravenous, inhaled }\end{array}$ & $\begin{array}{l}\text { Can be combined with triptans } \\
\text { to achieve more efficacy } \\
\text { Relief of pain and associated } \\
\text { symptoms }\end{array}$ & $\begin{array}{l}\text { Usually not useful } \\
\text { for severe attacks }\end{array}$ \\
\hline $\begin{array}{l}\text { Acetaminophen } \\
\text { (paracetamol } \\
\text { in Europe) }\end{array}$ & $\lg$ & Oral, endovenous & $\begin{array}{l}\text { Can be combined with antiemetics } \\
\text { (as metoclopramide), increasing } \\
\text { its efficacy considerably (in some } \\
\text { studies similar to sumatriptan) }\end{array}$ & $\begin{array}{l}\text { Generally does } \\
\text { not work with } \\
\text { moderate-severe } \\
\text { attacks }\end{array}$ \\
\hline Triptans & $\begin{array}{l}\text { Depending on type of triptan and } \\
\text { route of administration } \\
\text { - Sumatriptan: oral } 50-100 \mathrm{mg} \text {, } \\
\text { inhaled I0-20 mg, rectally } 25 \mathrm{mg} \text {, } \\
\text { transdermal patch } 6.5 \mathrm{mg} \\
\text { - Almotriptan: oral } 12.5 \mathrm{mg} \\
\text { - Zolmitriptan: oral and oral } \\
\text { dispersible } 2.5-5 \mathrm{mg} \text {, inhaled } 5 \mathrm{mg} \\
\text { - Eletriptan: oral } 20-80 \mathrm{mg} \\
\text { - Naratriptan: oral } 2.5 \mathrm{mg} \\
\text { - Rizatriptan: oral and oral } \\
\text { dispersible 5-10 mg } \\
\text { - Frovatriptan oral } 2.5 \mathrm{mg}\end{array}$ & $\begin{array}{l}\text { Oral, oral dispersible, } \\
\text { subcutaneous, } \\
\text { inhaled, rectal }\end{array}$ & $\begin{array}{l}\text { The group with highest efficacy } \\
\text { Specific treatment for migraine } \\
\text { Able to relieve severe attacks of } \\
\text { migraine and its associated } \\
\text { symptoms (nausea and vomiting) } \\
\text { Can be combined with NSAIDs } \\
\text { and simple analgesics } \\
\text { Can be administered per different } \\
\text { nonoral vials }\end{array}$ & $\begin{array}{l}\text { Expensive } \\
\text { Not recommended } \\
\text { in patients } \\
\text { with elevated } \\
\text { cardiovascular risk }\end{array}$ \\
\hline Ergots & $\begin{array}{l}\text { Dihydroergotamine (DHE): } \\
\text { parenteral } 0.5-\mathrm{I} \mathrm{mg} \text {; intranasal } \\
\text { Ergotamine: } \mathrm{I}-2 \mathrm{mg} \text { in suppositories }\end{array}$ & $\begin{array}{l}\text { Oral, rectal, } \\
\text { intravenous, inhaled }\end{array}$ & $\begin{array}{l}\text { Low price } \\
\text { Good efficacy } \\
\text { Can be combined with } \\
\text { antiemetics }\end{array}$ & $\begin{array}{l}\text { Elevated risk of } \\
\text { overuse } \\
\text { Can increase } \\
\text { nausea and } \\
\text { vomiting }\end{array}$ \\
\hline
\end{tabular}

Abbreviations: ASA, acetylsalicylic acid; NSAIDs, nonsteroidal anti-inflammatory drugs.

attacks, when nonoral treatment is required due to nausea or vomiting. When compared to subcutaneous sumatriptan, accompanying symptoms improved with both treatments to a similar extent. Therefore, intravenous aspirin in acute migraine attacks with nausea or vomiting is an alternative treatment to triptans or ergotics, with fewer side effects. ${ }^{51-54}$

Acetaminophen (paracetamol in Europe) 1,000 mg is an effective treatment for nonsevere acute migraine attacks. The addition of $10 \mathrm{mg}$ metoclopramide to acetaminophen gives short-term efficacy equivalent to oral sumatriptan $100 \mathrm{mg}$. Therefore, acetaminophen, especially in cotherapy with an antiemetic, can be an option of treatment in mild-acute migraine attacks. ${ }^{55}$

Caffeine stimulates gastrointestinal absorption, induces vasoconstriction, and reduces the activity of serotonergic neurons in the brain stem. Therefore, when caffeine is added to other analgesics (eg, drinking a cup of coffee or using combined tablets of caffeine with aspirin, ibuprofen, or ergots) their effect increases, but the risk of dependence and overuse increases too. ${ }^{56,57}$

\section{Triptans}

Triptans and ergots are the only migraine-specific abortive medications available nowadays. Triptans are agonists of the 5-hydroxytryptamine $(\mathrm{HT})_{1 \mathrm{~B}}$ and $5-\mathrm{HT}_{1 \mathrm{D}}$ receptors. The stimulation of these receptors decreases the excitability of the trigeminocervical nucleus cells relieving migraine attacks. Several clinical trials have demonstrated the superiority of triptans over ergots. ${ }^{58}$ Triptans are very effective not only at reducing migraine symptoms but also at restoring patients' normal activity. Some studies in healthy volunteers have shown indirect evidence for relaxation of the stomach and distal esophagus after administration of sumatriptan, probably secondary to action on the 5-HT - -like receptor. ${ }^{59,60}$ Therefore, as has been suggested before, triptans may have a central effect in nausea and vomiting relief. 
Table 2 Management of nausea and vomiting in migraine

\begin{tabular}{|c|c|c|c|}
\hline \multirow[t]{6}{*}{ Main goals } & \multicolumn{3}{|l|}{ I. Stop migraine attack itself } \\
\hline & \multicolumn{3}{|l|}{ - Early onset of treatment } \\
\hline & \multicolumn{3}{|l|}{ - With the effective drugs } \\
\hline & \multicolumn{3}{|l|}{ - At the effective doses } \\
\hline & \multicolumn{3}{|c|}{ - Alternative nonoral routes of administration, if needed } \\
\hline & \multicolumn{3}{|l|}{ 2. Symptomatic treatment } \\
\hline \multirow[t]{20}{*}{ Outpatient settings } & Migraine and nausea & - NSAIDs & Oral or rectal \\
\hline & \multirow[t]{10}{*}{ without vomiting } & - Or triptans & Oral or nonoral \\
\hline & & \multicolumn{2}{|l|}{ - And antiemetics } \\
\hline & & $>$ Metoclopramide & 10 mg/8 hours orally \\
\hline & & \multirow[t]{2}{*}{$>$ Domperidone } & $10-20 \mathrm{mg} / 6-8$ hours orally \\
\hline & & & 60 mg/8-12 hours rectally \\
\hline & & $>$ Trimethobenzamide & $250-300 \mathrm{mg} / 6-8$ hours orally \\
\hline & & $>$ Prochlorperazine & $5-10 \mathrm{mg} / 6-8$ hours orally \\
\hline & & $>$ Promethazine & $25 \mathrm{mg} / \mathrm{I} 2$ hours rectally \\
\hline & & \multirow[t]{2}{*}{$>$ Dimenhydrinate } & $12.5-25 \mathrm{mg} / 4-6$ hours orally/rectally \\
\hline & & & $50-100 \mathrm{mg}$ orally \\
\hline & \multirow{7}{*}{$\begin{array}{l}\text { Migraine with nausea } \\
\text { and vomiting } \\
\text { - Avoid oral drugs }\end{array}$} & \multicolumn{2}{|l|}{ - First-choice treatment } \\
\hline & & o Triptans, and antimetics & Subcutaneous, intranasal, rectal, \\
\hline & & & or transdermal patches \\
\hline & & \multicolumn{2}{|l|}{$\mathrm{o} \pm$ rectal antiemetics } \\
\hline & & $>$ promethazine & $12.5-25 \mathrm{mg} / 4-6$ hours rectally \\
\hline & & $>$ prochlorperazine & $25 \mathrm{mg} / \mathrm{I} 2$ hours rectally \\
\hline & & $\begin{array}{l}\text { - Unresponsiveness or no access } \\
\text { to other abortive treatments }\end{array}$ & Intranasal DHE or ergotamine suppositories \\
\hline & High frequency of nausea and & \multirow{2}{*}{\multicolumn{2}{|c|}{$\begin{array}{l}\text { - Combine an oral antiemetic, before the onset of nausea and vomiting } \\
\text { - Consider prophylactic migraine treatment }\end{array}$}} \\
\hline & vomiting within migraine attacks & & \\
\hline \multirow[t]{7}{*}{ Inpatient settings } & \multicolumn{3}{|l|}{ - Parenteral antiemetics } \\
\hline & $>$ Metoclopramide & & 10 mg/8 hours intramuscularly/intravenously \\
\hline & $>$ Prochlorperazine & & $\begin{array}{l}5-10 \mathrm{mg} / 6-8 \text { hours intramuscularly/ } \\
\text { intravenously }\end{array}$ \\
\hline & \multicolumn{2}{|l|}{$>$ Promethazine } & $\begin{array}{l}\text { I } 2.5-25 \mathrm{mg} / 4-6 \text { hours intramuscularly/ } \\
\text { intravenously }\end{array}$ \\
\hline & \multicolumn{2}{|l|}{$>$ Trimethobenzamide } & 200 mg/6-8 hours intramuscularly \\
\hline & \multicolumn{2}{|l|}{$>$ Dimenhydrinate } & 50-100 mg intramuscularly/intravenously \\
\hline & \multicolumn{3}{|c|}{$\begin{array}{l}\text { Associated if needed with parenteral NSAIDs, triptans, DHE, } \\
\text { neuroleptics, or corticosteroids, among others }\end{array}$} \\
\hline
\end{tabular}

Abbreviations: NSAIDs, nonsteroidal anti-inflammatory drugs; DHE, dihydroergotamine.

Sumatriptan has documented efficacy in relieving both migraine and associated symptoms, such as nausea and vomiting. In the 1990s, several studies reported an important delay of gastric emptying induced by sumatriptan in healthy humans. A further delay in gastric emptying caused by sumatriptan in migraine patients who already have delayed gastric emptying could increase nausea and epigastric symptoms. The impact of this gastric motor effect of sumatriptan in people with migraine is a paradox. Sumatriptan is reported both to relieve the nausea of a migraine attack and to have nausea as a side effect. In patients with functional dyspepsia, sumatriptan is also reported to improve gastric accommodation of a meal and reduce perception of gastric distension, relieving epigastric symptoms. Therefore, reduced visceral perception could be a mechanism involved in reducing nausea during a migraine attack in sumatriptan users.
Nevertheless, there are no available data to support definite conclusions, and further studies are required. ${ }^{8}$

All triptans are available as oral tablets (sumatriptan, rizatriptan, zolmitriptan, naratriptan, almotriptan, frovatriptan, and eletriptan). The only triptan that can be administered as a subcutaneous injection is sumatriptan. Some triptans are also available through newer routes of administration, such as rectal suppositories (sumatriptan, not available in many countries) and intranasal sprays (sumatriptan and zolmitriptan). In addition, rizatriptan and zolmitriptan are available as orally disintegrating tablets too. ${ }^{61}$ Recently approved by the US Food and Drug Administration (FDA), sumatriptan may be administered transdermally as transdermal iontophoretic patches as well. ${ }^{62}$

These alternative nonoral routes of administration (subcutaneous, intranasal, and rectal) and oral disintegrating tablets offer a useful alternative delivery system to conventional 
tablets for patients who have difficulty swallowing pills and for patients whose nausea and/or vomiting impede swallowing tablets and/or make the likelihood of complete absorption unpredictable. ${ }^{61}$ These alternative formulations offer migraineurs the possibility of using abortive treatment at the onset of migraine attacks without the need of liquids, anytime and anywhere.

Although the effect of triptan nasal sprays depends partially on nasal mucosal absorption, a significant amount of drug is swallowed, transits the stomach, and is absorbed in the small intestine. Therefore, a big part of their action probably depends on gastrointestinal absorption. On the other hand, subcutaneous sumatriptan injection (with or without a needle) is the fastest available triptan, as it avoids the gastrointestinal tract and is rapidly absorbed. ${ }^{62}$ Therefore, subcutaneous sumatriptan is the ideal triptan in patients with vomiting.

Zolmitriptan is available as a nasal spray formulation with proven efficacy, high tolerance, and a very fast onset of action. Zolmitriptan has been detected in plasma 2 minutes after intranasal administration in the majority of patients, compared to 10 minutes after oral administration. This may explain the faster migraine relief reported by patients when using intranasal zolmitriptan compared to oral zolmitriptan; however, the most intranasal absorption of the triptans is zolmitriptan at about $30 \% .^{63}$

Sumatriptan $25 \mathrm{mg}$ administered rectally is an effective treatment for headache pain relief and functional disability reduction, ${ }^{64}$ but it is not available in the US. In the same way, intranasal sumatriptan is also effective as an abortive treatment for acute migraine attacks, and relieving pain, nausea, photophobia, phonophobia, and functional disability. ${ }^{65}$ As stated before, sumatriptan is the only triptan that is also available as a subcutaneous injection, but the invasiveness and discomfort of administration, the high incidence of adverse events, and the high recurrence rates limit its use in many migraine patients. Nevertheless, subcutaneous sumatriptan is still the fastest and most effective triptan for acute migraine attacks.

Newer alternative routes of administration for triptans that avoid oral absorption are currently being investigated. Sumatriptan transdermal patches (such as NP101-Zelrix ${ }^{\text {TM}}$; NuPathe Inc, Conshohocken, PA, USA) have been studied in several clinical trials. This delivery bypasses hepatic first-pass metabolism and also avoids gastric transit delay. A randomized, double-blind, multicenter, Phase III study with sumatriptan transdermal patches demonstrated excellent tolerability (with no triptan-related adverse events) and superior efficacy versus placebo. Nausea, photophobia, and phonophobia relief 2 hours after patch activation was significantly more frequent among patients treated with the sumatriptan iontophoretic transdermal system compared to placebo. Transdermal sumatriptan is also superior to oral triptans for migraine patients whose baseline nausea causes them to delay or avoid acute treatment. ${ }^{66}$ Therefore, as suggested by Vikelis et al, ${ }^{16}$ sumatriptan transdermal iontophoretic patches are a promising and good choice of treatment in patients with important and intolerable triptan-related adverse events, as well as in migraineurs with disabling nausea and vomiting who experience poor absorption of oral medication. ${ }^{67,68}$ Sumatriptan transdermal patches were approved by the FDA recently. ${ }^{16}$

\section{Ergots}

Ergot alkaloids, such as ergotamine or dihydroergotamine (DHE), have been the only "specific" treatment for migraine for decades. Nowadays, the scientific community recommends a restricted employment of ergots in migraineurs, due to the risk of overuse and chronic daily headache and their cardiovascular side effects (as they are nonselective drugs). Additionally, ergots probably are lesser-recommended drugs for acute migraine attacks with nausea and vomiting, as one of their main side effects is nausea and vomiting itself. ${ }^{69}$ Therefore, they should be avoided in newly diagnosed migraine patients. Their use is limited to patients without any formal contraindications who have already taken ergots in the past and have a low frequency of episodes (fewer than one per week).$^{70}$ Ergots may also be useful in patients with long-lasting migraine attacks or with high recurrence rates. One option in these cases is the administration of ergotamine rectal suppositories (1-2 mg) with an antiemetic (10 mg metoclopramide oral tablets, or 25-100 mg chlorpromazine or $25 \mathrm{mg}$ prochlorperazine rectal suppositories if the patient is vomiting).

DHE has low oral bioavailability, which limits its use to parenteral and intranasal routes of administration. DHE may be useful in patients with severe nausea and vomiting that impede other routes of administration, when there is unresponsiveness to other abortive treatments or no access to other drugs (for economic or supply reasons, among others). These patients should be instructed in self-administration of the drug before starting treatment. ${ }^{2}$

Although DHE's effect is slower than subcutaneous sumatriptan's effect, their efficacy in pain relief after 2 hours of administration is similar, with a lower headache-recurrence rate within 24 hours for DHE. Nevertheless, when DHE is given intravenously, nausea may worsen. Therefore, antiemetics should be added to parenteral DHE. An effective option of 
treatment is to administer $0.5-1 \mathrm{mg}$ of intravenous DHE with $10 \mathrm{mg}$ of intravenous metoclopramide or prochlorperazine (the latter, given alone, is able to reverse a migraine episode by itself in many cases). ${ }^{70}$

Injectable DHE, although effective, is considered invasive and inconvenient, and intranasal DHE is associated with inconsistent systemic dosage delivery. An orally inhaled and self-administered formulation of DHE delivered to the systemic circulation, known as MAP0004, has been developed. MAP0004 aerosol DHE provides desirable activation of $5-\mathrm{HT}_{1 \mathrm{~B} / \mathrm{DD}}$ receptors, resulting in effective antimigraine effects. Unlike intravenous DHE, MAP0004 is less likely to bind with other serotonergic, adrenergic, and dopaminergic receptors, resulting in fewer unwanted side effects. Unlike conventional intravenous DHE, which is generally administered with an antinausea medication, MAP0004 administered by itself shows no statistically significant drug-related increase in nausea. In addition, MAP0004 is less arterio-constrictive than intravenous DHE. MAP0004 has been proven to be effective and well tolerated for the acute treatment of migraine, providing statistically significant pain relief and freedom from photophobia, phonophobia, and nausea in adults with migraine compared with placebo. Both Phase II and III clinical trials support antimigraine efficacy with superior toleration with MAP0004 compared with intravenous DHE. MAP0004 may be a promising first-line agent for migraine treatment, with lower rates of nausea and vomiting than other DHE routes of administration..$^{71-73}$

\section{Dopamine antagonists}

Dopamine antagonists, commonly used for psychosis and nausea, have an established role in the treatment of migraine. Neuroleptics, which antagonize the dopamine $\mathrm{D}_{2}$ receptor, also have variable activity as alpha-adrenergic blockers, antiserotonergics, anticholinergics, and antihistamines. Their actions on dopamine are likely the reason for their efficacy in treating nausea and acute migraine. These drugs are many times the first-line agents in the emergency room setting for migraine, especially for patients with nausea and vomiting. They are also an effective option in patients who have contraindications to migraine-specific medications or NSAIDs or in pregnant migraine patients. Neuroleptic medications are also commonly used in the treatment of status migrainosus or medication-overuse headache, as it has been suggested that dopamine is particularly important in chronic pain. Their main adverse events are sedation, akathisia, dystonic reactions, neuroleptic malignant syndrome, or movement disorders with long-term use. Therefore, they should be used carefully to try to and avoid these side effects. Some newer atypical neuroleptic agents appear promising for both acute and prophylactic migraine treatment, with a lower risk of adverse events. ${ }^{70}$ Diphenhydramine may be coadministered to avoid many extrapyramidal adverse effects of antidopaminergic drugs.

Combinations containing oral metoclopramide plus an analgesic may be useful in patients with migraines, contraindications, or undesirable adverse effects with triptans, or when cost is an issue. However, this combination will likely be less effective than oral triptans in the treatment of migraine and its associated symptoms. ${ }^{74}$

\section{Preventative treatment}

Prophylactic migraine treatment is indicated when migraines are frequent (three or more attacks per month), or long lasting (attack duration longer than 48 hours), or account for a significant amount of total disability. Therefore, when migraine attacks are not frequent, but associated with severe, long-lasting, or disabling symptoms or unresponsiveness to abortive medications, preventive treatment may be started (as long as the patient agrees). ${ }^{74,75}$ For this reason, patients who have disabling and invalidating nausea and vomiting resistant to acute treatment can be started on prophylactic drugs, despite the frequency of migraine attacks. One case series described that about $75 \%$ of patients on amitriptyline had their nausea fully or partially relieved. ${ }^{21,76}$ Tricyclics may act on afferent pathways involved in the central regulation of vomiting. Therefore, tricyclic antidepressants, and specially amitriptyline, may be an effective prophylactic treatment of choice in migraine patients with disabling nausea and vomiting, but further studies are required. ${ }^{76}$

A reduction in frequency and in some cases intensity of migraine attacks has been described with all preventive treatments, but there are no clear data on their efficacy in preventing nausea and vomiting. Although it is reasonable to think that if preventive treatments decrease the frequency of migraine attacks, the frequency of nausea and vomiting must decrease too, further studies are needed to confirm this hypothesis.

\section{Non pharmacological approaches}

Nonpharmacological approaches for nausea and vomiting management have been described. Acupuncture and acupressure, based on traditional Chinese medicine, are sometimes used for nausea and vomiting relief. There is evidence that the stimulation of the acupuncture point PC6 (Neiguan) alleviates chemotherapy-induced nausea and vomiting and motion 
sickness. A recent study ${ }^{1}$ published in 2012 examined the efficacy of acupressure in the control of migraine-associated nausea in 40 patients. Highly statistically significant reduction in the intensity of nausea and the need for rescue antiemetic medication were found when compared to sham. ${ }^{1}$ Therefore, acupressure may be an option of treatment in patients who prefer alternative medicines and decline drug use.

\section{Status migrainosus}

In regard to status migrainosus, many cases may require hospital admission to achieve an optimal management. Status migrainosus refers to severe migraine episodes that last more than 72 hours, usually accompanied by severe nausea and vomiting, that can impede oral administration of drugs. In these cases, fluid replacement, correction of fluid and electrolyte imbalances (if present) and quitting of nausea and vomiting with intravenous metoclopramide, chlorpromazine, or prochlorperazine is needed. Neuroleptics may be useful because of their sedative and antiemetic action (eg, $100 \mathrm{mg}$ of intravenous tiapride dissolved in dextrose). Administration of intravenous corticosteroids, such as $4-8 \mathrm{mg}$ of dexamethasone every 6-8 hours or 20-40 mg of prednisolone every 6-8 hours, with a subsequent tapering dose for 3-4 days, is also effective in controlling headache and the accompanying symptoms. Analgesics and NSAIDs have a minor role in these cases, but may be helpful as adjuvants when combined with other drugs. Nonoral formulations of triptans (such as $6 \mathrm{mg}$ of subcutaneous sumatriptan, 10-20 mg of intranasal sumatriptan, or $5 \mathrm{mg}$ of intranasal zolmitriptan) are the initial treatment of choice. Intravenous DHE $(0.5 \mathrm{mg})$ combined with intravenous antiemetics is effective too. It can be administered every 8 hours if the headache does not stop. ${ }^{75}$

\section{Management of migraine, nausea, and vomiting in special populations}

Migraine management in special populations, such as pediatric populations, pregnant women, or the elderly, may be difficult and requires selection of appropriate and safe medications for patients in these special circumstances.

\section{Migraine and pregnancy}

Migraine improves during pregnancy in $50 \%-80 \%$ of patients, and attacks typically diminish by the end of the first trimester. However, attacks may remain unchanged, continue, or worsen. Infrequently, migraine may appear for the first time during pregnancy. ${ }^{77}$ Women who have had menstrual migraine and migraine onset at menarche tend to experience no migraine during pregnancy. The positive effects of pregnancy on migraine and the possible worsening postpartum effects are probably related to the uniformly high and stable estrogen levels during pregnancy and the rapid falloff thereafter. ${ }^{78}$ Safety of drugs used for migraine is an important issue during pregnancy. Nondrug therapies (relaxation, sleep, massage, ice packs, biofeedback) should be tried first to treat migraine in women who are pregnant. ${ }^{78,79}$ For treatment of acute migraine attacks, 1,000 mg of paracetamol (acetaminophen), preferably as a suppository, is considered the first-choice drug treatment. The risks associated with use of aspirin and NSAIDs are considered to be small when the agents are taken episodically and if they are avoided during the last trimester of pregnancy (risks of maternal or fetal bleeding and premature closure of the fetal ductus arteriosus). There is limited evidence about triptan safety during pregnancy, therefore they should be avoided in these patients. DHE and ergotamine are contraindicated in women who are pregnant. Prochlorperazine and promethazine hydrochloride for treatment of nausea are unlikely to be harmful during pregnancy. Metoclopramide is probably acceptable to use during the second and third trimesters. Domperidone is also safe in pregnant women. Prophylactic treatment is rarely indicated because of potential teratogenicity. When prophylactic treatment is used, beta-blockers are the preferred treatment (stopping 2 weeks before partum). ${ }^{77-79}$ Ondansetron use cannot be assumed to be safe during pregnancy. An increased risk of cleft palate associated with ondansetron has been suggested, and potentially serious QT prolongation and Torsades de pointes have been associated with ondansetron use. ${ }^{80}$

\section{Common migraine treatments in breastfeeding women}

Many commonly used migraine medications may be compatible with breastfeeding based on expert recommendations. Ibuprofen, diclofenac, and eletriptan are among acute medications with low levels in breast milk, but studies of triptans are limited. Toxicity is a concern with aspirin, due to an association with Reye's syndrome, and with opioids, due to an association with sedation or apnea. Clinicians treating migraine should discuss treatments options shortly before and within a few months after delivery, in consultation with the obstetrician and pediatrician. ${ }^{81}$

\section{Migraine in adolescents and children}

Although migraine is a common occurrence in children and adolescents, its diagnosis and treatment present unique challenges. Evidence for the pharmacological treatment 
of acute migraine in children is very poor, and evidence for adolescents is better but still limited. ${ }^{82}$ Generally, acetaminophen and ibuprofen are accepted as drugs of first choice, even though the evidence is poor for the former and limited for the latter. Among 14 studies on triptans in adolescents, nine showed some superiority over placebo with respect to pain relief and pain freedom, and among six studies in children, five suggested some superiority over placebo. Sumatriptan nasal spray and zolmitriptan nasal spray have been approved for adolescents in Europe; and almotriptan has been approved for adolescents in the US as has rizatriptan for patients aged 6-17 years. ${ }^{82}$ If simple analgesics are insufficient and if nausea or vomiting is a prominent symptom, then adding an antiemetic agent (dimenhydrinate, metoclopramide, trimethobenzamide hydrochloride) may be helpful. ${ }^{77}$ The literature data on prophylaxis are conflicting: flunarizine and topiramate are probably effective; for other drugs (including cyproheptadine, amitriptyline, divalproate, and levetiracetam), there is insufficient evidence in children. The results from the use of propranolol are conflicting, whereas nimodipine and clonidine have shown to be ineffective. ${ }^{82,83}$

\section{Treatment of elderly patients with migraine}

Managing older migraine patients necessitates particular caution, including taking into account possible pharmacological interactions associated with the greater use of drugs for concomitant diseases in the elderly. Comorbid diseases may prohibit the use of some medications. Moreover, older patients are more likely than younger ones to develop adverse effects. Paracetamol is the safest drug for symptomatic treatment of migraine in the elderly. NSAID use should be limited because of potential gastrointestinal adverse events, and triptan use is not recommended, even in the absence of cardiovascular or cerebrovascular risk. Antiemetics can be used, but cautiously, especially in Parkinson's disease patients. Selection of a prophylactic treatment, when needed, should be influenced by the patient's comorbidities, and should be directed toward those drugs that are believed to have fewer adverse effects and a better safety profile. ${ }^{84}$

\section{Management of migraine and nausea and vomiting in patients with liver or renal failure}

This patient group may be very difficult based on treatment side effects and contraindications. Acetaminophen is contraindicated in hepatic insufficiency. Aspirin and NSAIDs may cause renal impairment, and are contraindicated in gastrointestinal ulcers, bleeding diathesis, renal insufficiency, and allergy. Opioids may produce constipation or sedation. Antiemetic agents may cause sedation and extrapyramidal side effects being contraindicated in Parkinson's disease. Therefore, treating migraine in special populations can be difficult and requires the selection of appropriate and safe medications for patients in special circumstances. ${ }^{77}$

\section{Conclusion}

The main treatment of nausea and vomiting in migraine is to cease the migraine attack itself as soon as possible, with effective drugs at effective doses, seeking if necessary alternative routes of administration. Therefore, the early onset of treatment once headache begins must be one of the main aims of migraine management. Trying to avoid individual stimuli that trigger nausea and vomiting in some patients (such as particular meals or odors) may be recommended also.

In outpatient settings, migraine attacks that are accompanied by nausea without vomiting can be treated with oral NSAIDs or with oral or nonoral triptans. These drugs can be combined with oral antiemetics that increase intestinal motility even when vomiting is not present, improving the response to oral medications. In fact, patients who have a high frequency of nausea and vomiting during their migraines should combine an oral antiemetic (such as $10 \mathrm{mg}$ of metoclopramide or domperidone) to NSAIDs or triptans before the onset of nausea and vomiting. Oral-disintegration triptan tablets are also a good option of treatment in migraine attacks that are accompanied by nausea without vomiting.

When migraine attacks are associated with vomiting, oral drugs should be avoided. In these cases, the first choice of treatment is subcutaneous, intranasal, or rectal triptans to guarantee drug bioavailability. Sumatriptan transdermal iontophoretic patches, recently approved by the FDA, may be an alternative option. In patients with severe nausea and vomiting with unresponsiveness to other abortive treatments or no access to other drugs, DHE may be useful. When migraine patients have frequent, severe, and disabling nausea and vomiting, despite acute abortive treatment, prophylactic drugs may be started. Migraine attacks with nausea and vomiting at the emergency department can be treated with parenteral NSAIDs, nonoral triptans, and/or intravenous antiemetics.

Status migrainosus will usually require hospital admission with fluid replacement and correction of hydroelectrolytic imbalances. In these cases, nausea and vomiting can 
be managed with intravenous antiemetics, accompanied if needed by parenteral NSAIDs, triptans, DHE, neuroleptics, corticosteroids, or even valproate, among others.

Migraine is a very common disorder that frequently is associated with nausea and vomiting, which may be even more disabling than the headache itself, producing a great burden on patient quality of life. Therefore, acknowledgment and achievement of optimal management of nausea and vomiting in migraine is crucial to improve patient outcomes.

\section{Disclosure}

The authors report no conflicts of interest in this work.

\section{References}

1. Mateos V, Pareja JA, Pacual J. Tratado de Cefaleas. [Headache Treatment]. Editorial Luzán, Madrid, 2009. Spanish.

2. Bradley WG, Daroff RB, Fenichel GM, Jankovic J. Neurology in Clinical Practice. 5th ed. Oxford: Butterworth-Heinemann; 2007.

3. Leira R, Láinez JM, Pascual J, et al. Estudio español de calidad de vida en migraña (I). Perfil del paciente con migraña que acude a consultas de neurología. [Spanish study of quality of life in migraine (I). Profile f migraine patient treated in outpatients clinics.]. Neurologia. 1998;13:287-291. Spanish.

4. Rasmussen BK, Olesen J. Migraine with aura and migraine without aura: an epidemiological study. Cephalalgia. 1992;12:221-228.

5. Campbell JK. Manifestations of migraine. Neurol Clin. 1990;8: 841-855.

6. Lance JW, Anthony M. Some clinical aspects of migraine. Arch Neurol. 1996;15:356-361.

7. Rasmussen BK, Jensen R, Olesen J. A population-based analysis of the diagnostic criteria of the International Headache Society. Cephalalgia. 1991;11:129-134.

8. Lipton RB, Stewart WF, Diamond S, Diamond ML, Reed M. Prevalence and burden of migraine in the United States: data from the American Migraine Study II. Headache. 2001;41:646-657.

9. Silberstein SD. Migraine symptoms: results of a survey of self-reported migraineurs. Headache. 1995;35:387-396.

10. Malick A, Burstein R. Cells of origin of the trigeminohypothalamic tract in the rat. J Comp Neurol. 1998;400:125-144.

11. Weiller C, May A, Limmroth V, et al. Brain stem activation in spontaneous human migraine attacks. Nat Med. 1995;1:658-660.

12. Bolay H, Reuter U, Dunn AK, Huang Z, Boas DA, Moskowitz MA. Intrinsic brain activity triggers trigeminal meningeal afferents in a migraine model. Nat Med. 2002;8:136-142.

13. Burstein R, Jakubowski M. Neural substrate of depression during migraine. Neurol Sci. 2009;30 Suppl 1:S27-S31.

14. Goadsby PJ, Lipton RB, Ferrari MD. Migraine - current understanding and treatment. $N$ Engl J Med. 2002;346:257-270.

15. Stovner LJ, Hagen K, Jensen R, et al. The global burden of headache: a documentation of headache prevalence and disability worldwide Cephalalgia. 2007;27:193-210.

16. Vikelis M, Mitsikostas DD, Rapoport A. Sumatriptan transdermal iontophoretic patch (NP101-Zelrix ${ }^{\mathrm{TM}}$ ): review of pharmacology, clinical efficacy, and safety in the acute treatment of migraine. Neuropsychiatr Dis Treat. 2012;8:429-434.

17. Kelman L, Tanis D. The relationship between migraine pain and other associated symptoms. Cephalalgia. 2006;26:548-553.

18. Kelman L, Tanis D. The relationships between migraine pain and other associated symptoms. Cephalalgia. 2006;26:548-553.
19. Stadler M, Bardiau F, Seidel L, Albert A, Boogaerts JG. Difference in risk factors for postoperative nausea and vomiting. Anaesthesiology. 2003;98:46-52.

20. Hirst B, Noble B. Migraine as a cause of persistent nausea or vomiting in palliative care: a case series. J Pain Symptom Manage. 2009;37: 918-922.

21. Aurora SK, Kori SH, Barrodale P, McDonald SA, Haseley D. Gastric stasis in migraine: more than just a paroxysmal abnormality during a migraine attack. Headache. 2006;46:57-63

22. Nimmo WS. Gastric emptying and drug absorption. In: Prescott LF, Nimmo WS, editors. Drug Absorption. New York: Springer; 1980:11-20.

23. Volans GN. Migraine and drug absorption. Clin Pharmacokinet. 1978;3: 313-318.

24. Volans GN. The effect of metoclopramide on the absorption of effervescent aspirin in migraine. Br J Clin Pharmacol. 1975;2: $57-63$.

25. Tokola RA, Neuvoven PJ. Effect of migraine attacks on paracetamol absorption. Br J Clin Pharmacol. 1984;18:867-871.

26. Tokola RA. The effect of metoclopramide and prochlorperazine on the absorption of effervescent paracetamol in migraine. Cephalalgia. 1988;8:139-147.

27. Tokola RA, Kangasniemi P, Neuvonen PJ, Tokola O. Tolfenamic acid, metoclopramide, caffeine and their combinations in the treatment of migraine attacks. Cephalalgia. 1984;4:253-263.

28. Mosek A, Novak V, Opfer-Gehrking TL, Swanson JW, Low PA. Autonomic dysfunction in migraineurs. Headache. 1990;39:108-117.

29. Avnon Y, Nitzan M, Sprecher E, Rogowsky Z, Yarnitsky D. Autonomic asymmetry in migraine: augmented parasympathetic activation in left unilateral migraineurs. Brain. 2004;127:2099-2108.

30. Peroutka SJ. Migraine: a chronic sympathetic nervous system disorder Headache. 2004;44:53-64.

31. Shechter A, Stewart WF, Silberstein SD, Lipton RB. Migraine and autonomic nervous system function: a population-based, case-control study. Neurology. 2002;58:422-427.

32. Welch KM, Nagesh V, Aurora SK, Gelman N. Periaqueductal gray matter dysfunction in migraine: cause or the burden of illness? Headache. 2001;41:629-637.

33. Boles RG. High degree of efficacy in the treatment of cyclic vomiting syndrome with combined co-enzyme Q10, L-carnitine and amitriptyline, a case series. BMC Neurol. 2011;11:102.

34. Kowalczyk M, Parkman H, Ward L. Adult cyclic vomiting syndrome successfully treated with intranasal sumatriptan. Intern Med. 2010;25: 88-91.

35. Lipton RB, Bigal ME. Ten lessons on the epidemiology of migraine. Headache. 2007;47 Suppl 1:S2-S9.

36. Stadler M, Bardiau F, Seidel L, Albert A, Boogaerts JG. Difference in risk factors for postoperative nausea and vomiting. Anaesthesiology. 2003; $98: 46-52$.

37. Burstein R, Levy D, Jakubowski M. Effects of sensitization of trigeminovascular neurons to triptan therapy during migraine. Rev Neurol (Paris). 2005;161:658-660.

38. Peroutka SJ. Beyond monotherapy: rational polytherapy in migraine. Headache. 1998;38:18-22.

39. Limmroth V, Kazarawa S, Diener HC. Acetylsalicylic acid in the treatment of migraine and other headache - a historical and current overview. Cephalalgia. 1999;19:545-551.

40. Lipton RB, Goldstein J, Baggis JS, Yataco AR, Sorrentino JV, Quiring JN. Aspirin is efficacious for the treatment of acute migraine. Headache. 2005;45:283-292.

41. Codispoti JR, Prior MJ, Harte CM, Nelson EB. Efficacy of nonprescription doses of ibuprofen for treating migraine headache. A randomized controlled trial. Headache. 2001;41:665-679.

42. Tfelt-Hansen P, Rolan P. Nonsteroidal antiinflamatory drugs in the acute treatment of migraines. In: Olesen J, Goadsby PJ, Ramadan NM, TfeltHansen P, Welch KMA, editors. The Headaches. 3rd ed. Philadelphia: Lippincott Williams \& Wilkins; 2006:449-458. 
43. Mateos V. Tratamiento de la crisis aguda de migraña. [Treatment of acute migraine attacks.]. In: Mederer Hengstl S, editor. XI Curso Internacional de Cefaleas. [XI International Headache Course]. Madrid: Ergon; 2006:89-107. Spanish.

44. Rabbie R, Derry S, Moore RA, McQuay HJ. Ibuprofen with or without an antiemetic for acute migraine headaches in adults. Cochrane Database Syst Rev. 2010;10:CD008039.

45. Kirthi V, Derry S. Moore RA, McQuay HJ. Aspirin with or without an antiemetic for acute migraine headaches in adults. Cochrane Database Syst Rev. 2010;4:CD008041.

46. Lampl C, Voelker M, Diener HC. Efficacy and safety of 1,000 mg effervescent aspirin: individual patient data meta-analysis of three trials in migraine headache and migraine accompanying symptoms. J Neurol. 2007;264:705-712.

47. Pascual Gómez J, Oterino Durán A, Mateos Marcos V, Láinez Andrés JM. Migraña y cefalea tensional. [Migraine and tension headache]. In: Pascual J, editor. Tratado de Neurología Clínica. [Clincial neurology treatise] Madrid: Ars XXI; 2008:79-100. Spanish.

48. Gattani SG, Khabiya SS, Amrutkar JR, Kushare SS. Formulation and evaluation of bilayer tablets of metoclopramide hydrochloride and diclofenac sodium. PDA J Pharm Sci Technol. 2012;66:151-169.

49. González-Delgado M, De La Vega V, García J, Benavente L, Mateos V. $¿$ ¿ómo se atienden las cefaleas en el servicio de urgencias de un hospital de tercer nivel? [How are headaches attended in the emergency department of a tertiary hospital?] Neurologia. 2004;19:637-637. Spanish.

50. Pfaffenrath V, Fenzl E, Bregman D, Färkkila M. Intranasal ketorolac tromethamine $\left(\right.$ SPRIX $^{\circledR}$ ) containing $6 \%$ of lidocaine (ROX-828) for acute treatment of migraine: safety and efficacy data from a phase II clinical trial. Cephalalgia. 2012;32:766-777.

51. Limmroth V, May A, Diener H. Lysine-acetylsalicylic acid in acute migraine attacks. Eur Neurol. 1999;41(2)88-93.

52. Weatherall MW, Telzerow AJ, Cittadini E, Kaube H, Goadsby PJ. Intravenous aspirin (lysine acetylsalicylate) in the inpatient management of headache. Neurology. 2010;75:1098-1103.

53. Diener HC. Efficacy and safety of intravenous acetylsalicylic acid lysinate compared to subcutaneous sumatriptan and parenteral placebo in the acute treatmene of migraine. A double-blind, double-dummy, randomized, multicenter, parallel group study. The ASASUMAMIG Study Group. Cephalalgia. 1999;19:581-588.

54. Leniger T, Pageler L, Stude P, Diener HC, Limmroth V. Comparison of intravenous valproate with intravenous lysine-acetylsalicylic acid in acute migraine attacks. Headache. 2005;45:42-46.

55. Derry S, Moore RA, McQuay HJ. Paracetamol (acetaminophen) with or without an antiemetic for acute migraine headaches in adults. Cochrane Database Syst Rev. 2010;11:CD008040.

56. Anneken K, Evers S, Husstedt IW. Efficacy of fixed combinations of acetylsalicyclic acid, acetaminophen and caffeine in the treatment of idiopathic headache: a review. Eur J Neurol. 2010;17:534-e25.

57. Diener HC, Peil H, Aicher B. The efficacy and tolerability of a fixed combination of acetylsalicylic acid, paracetamol, and caffeine in patients with severe headache: a post-hoc subgroup analysis from a multicentre, randomized, double-blind, single-dose, placebo-controlled parallel group study. Cephalalgia. 2011;31:1466-1476.

58. Tfelt HP, Saxena PR, Dahlöf C, et al. Ergotamine in the acute treatment of migraine: a review and European consensus. Brain. 2000;123: 9-18.

59. Tack J, Coulie B, Wilmer A, Andriolli A, Janssens J. Influence of sumatriptan on gastric fundus tone and on the perception of gastric distension in man. Gut. 2000;46:468-473.

60. Moro E, Crema F, De Ponti F, Frigo G. Triptans and gastric accommodation: pharmacological and therapeutic aspects. Dig Liver Dis. 2004;36:85-92.

61. Gladstone JP, Gawel M. Newer formulations of the triptans: advances in migraine. Drugs. 2003;63:2285-2305.
62. Rapoport AM, Freitag F, Pearlman SH. Innovative delivery systems for migraine: the clinical utility of a transdermal patch for the acute treatment of migraine. CNS Drugs. 2010;24:929-940.

63. Uemura N, Onishi T, Mitaniyama A, et al. Bioequivalence and rapid absorption of zolmitriptan nasal spray compared with oral tablets in healthy Japanese subjects. Clin Drug Investig. 2005;25: 199-208.

64. Derry CJ, Derry S, Moore RA. Sumatriptan (rectal route of administration) for acute migraine attacks in adults. Cochrane Database Syst Rev. 2012;2:CD009664.

65. Derry CJ, Derry S, Moore RA. Sumatriptan (intranasal route of administration) for acute migraine attacks in adults. Cochrane Database Syst Rev. 2012;2:CD009663.

66. Goldstein J, Smith TR, Pugach N, Griesser J, Sebree T, Pierce M. A sumatriptan iontophoretic transdermal system for the acute treatment of migraine. Headache. 2012;52:1402-1410.

67. Schulman EA. Transdermal sumatriptan for acute treatment of migraineurs with baseline nausea. Headache. 2012;52:204-212.

68. Erlichson K, Waight J. Therapeutic applications for subcutaneous triptans in the acute treatment of migraine. Curr Med Res Opin. 2012;28: 1231-1238.

69. Marmura MJ. Use of dopamine antagonists in treatment of migraine. Curr Treat Options Neurol. 2012;14:27-35.

70. Azzopardi TD, Brooks NA. Oral metoclopramide as an adjunct to analgesics for the outpatient treatment of acute migraine. Ann Pharmacother. 2008;42:397-402.

71. Silberstein S. MAP0004: dihydroergotamine mesylate inhalation aerosol for acute treatment of migraine. Expert Opin Pharmacother. 2012;13: 1961-1968.

72. Aurora SK, Silberstein SD, Kori SH, et al. MAP0004, orally inhaled DHE: a randomized, controlled study in the acute treatment of migraine. Headache. 2011;51:507-517.

73. Tepper SJ, Kori SH, Goadsby PJ, et al. MAP0004, orally inhaled dihydroergotamine for acute treatment of migraine: efficacy of early and late treatments. Mayo Clin Proc. 2011;86(10):948-955.

74. Katsavara Z, Schneeweis S, Kurth T, et al. Incidence and predictors for chronicity of headache in patients with episodic migraine. Neurology. 2004;62:788-790.

75. Loder E, Biondi D. General principles of migraine management: the changing role of prevention. Headache. 2005;45 Suppl 1:S33-S47.

76. Prakash $\mathrm{C}$, Clouse RE. Clinical vomiting syndrome in adults: clinical features and response to tricyclic antidepressants. Am J Gastroenterol. 1999;94:2855-2860.

77. Gladstone JP, Eross EJ, Dodick DW. Migraine in special populations. Treatment strategies for children and adolescents, pregnant women, and the elderly. Postgrad Med. 2004;115:39-44.

78. Pfaffenrth V, Rehm M. Migraine in pregnancy: what are the safest treatment options? Drug Saf. 1998;19:383-388.

79. Jalilian N, Farkheri T, Daechin S, Vakilifar F. Migraine management in pregnancy. J Inj Violence Res. 2012;4:78.

80. Koren G. Motherisk update. Is ondansetron safe for use during pregnancy? Can Fam Physician. 2012;58:1092-1093.

81. Hutchinson S, Marmura MJ, Calhoun A, Lucas S, Silberstein S, Peterlin BL. Use of common migraine treatments in breast-feeding women: a summary of recommendations. Headache. 2013;53:614-627.

82. Wöber-Bingöl Ç. Pharmacological treatment of acute migraine in adolescents and children. Paediatr Drugs. 2013;15:235-246.

83. O'Brien HL, Kabbouche MA, Hershey AD. Treatment of acute migraine in the paediatric population. Curr Treat Options Neurol. 2010;12: 178-185.

84. Sarchielli P, Mancini ML, Calabresi P. Practical considerations for the treatment of elderly patients with migraine. Drugs Aging. 2006;23: $461-489$. 
Patient Related Outcome Measures

Dovepress

\section{Publish your work in this journal}

Patient Related Outcome Measures is an international, peer-reviewed, open access journal focusing on treatment outcomes specifically relevant to patients. All aspects of patient care are addressed within the journal and practitioners from all disciplines are invited to submit their work as well as healthcare researchers and patient support groups.

Submit your manuscript here: http://www.dovepress.com/patient-related-outcome-measures-journal
The manuscript management system is completely online and includes a very quick and fair peer-review system. Visit http://www.dovepress. com/testimonials.php to read real quotes from published authors. 